\title{
BMJ Open Correlates of the double burden of malnutrition among women: an analysis of cross sectional survey data from sub- Saharan Africa
}

Dickson Abanimi Amugsi, ${ }^{01}$ Zacharie Tsala Dimbuene, ${ }^{2,3}$ Catherine Kyobutungi ${ }^{1}$

To cite: Amugsi DA, Dimbuene ZT, Kyobutungi C. Correlates of the double burden of malnutrition among women: an analysis of cross sectional survey data from sub-Saharan Africa. BMJ Open 2019;9:e029545. doi:10.1136/ bmjopen-2019-029545

- Prepublication history for this paper is available online. To view these files, please visit the journal online (http://dx.doi. org/10.1136/bmjopen-2019029545).

Received 30 January 2019

Revised 24 May 2019

Accepted 30 May 2019

Check for updates

(C) Author(s) (or their employer(s)) 2019. Re-use permitted under CC BY-NC. No commercial re-use. See rights and permissions. Published by BMJ.

${ }^{1}$ Maternal and Child Wellbeing Unit, African Population and Health Research Center, Nairobi, Kenya

${ }^{2}$ Population Sciences and Development, University of Kinshasa, Kinshasa, The Democratic Republic of the Congo

${ }^{3}$ Social Analysis and Modeling Division, Statistics Canada, Ottawa, Canada

Correspondence to Dr Dickson Abanimi Amugsi; damugsi2002@yahoo.com

\section{ABSTRACT}

Objective To investigate the correlates of the double burden of malnutrition (DBM) among women in five subSaharan African countries.

Design Secondary analysis of Demographic and Health Surveys (DHS). The outcome variable was body mass index (BMI), a measure of DBM. The BMI was classified into underweight $\left(\mathrm{BMl}<18.50 \mathrm{~kg} / \mathrm{m}^{2}\right)$, normal weight $\left(18.50-24.99 \mathrm{~kg} / \mathrm{m}^{2}\right)$, overweight $\left(25.0-29.9 \mathrm{~kg} / \mathrm{m}^{2}\right)$ and obesity $\left(\geq 30.0 \mathrm{~kg} / \mathrm{m}^{2}\right)$.

Settings Ghana, Nigeria, Kenya, Mozambique and Democratic Republic of Congo (DRC).

Subjects Women aged 15-49 years $(n=64698)$.

Results Compared with normal weight women, number of years of formal education was associated with the likelihood of being overweight and obese in Ghana, Mozambique and Nigeria, while associated with the likelihood of being underweight in Kenya and Nigeria. Older age was associated with the likelihood of being underweight, overweight and obese in all countries. Positive associations were also observed between living in better-off households and overweight and obesity, while a negative association was observed for underweight. Breastfeeding was associated with less likelihood of underweight in DRC and Nigeria, obesity in DRC and Ghana, overweight in Kenya and overweight and obesity in Mozambique and Nigeria relative to normal weight. Conclusions Our analysis reveals that in all the countries, women who are breastfeeding are less likely to be underweight, overweight and obese. Education, age and household wealth index tend to associate with a higher likelihood of DBM among women. Interventions to address DBM should take into account the variations in the effects of these correlates.

\section{INTRODUCTION}

The double burden of malnutrition (DBM), which is the coexistence of both undernutrition and overnutrition in the same population across the life course, ${ }^{12}$ is a global public health problem. ${ }^{12}$ Data from the WHO indicate that in 2014, 1.9 billion adults aged 18 years and above were overweight, while over 600 million were obese globally. ${ }^{1}$ Similarly, in the same year, 462 million adults were
Strengths and limitations of this study

- Large nationally representative samples used, thereby providing more robust estimates of observed associations.

- The height and weight data used to compute the body mass index were objectively measured, reducing possible misclassification.

- Use of multicountry data helped unmask differences and commonalities in the effects of the correlates on double burden of malnutrition (DBM) across countries.

- The use of cross-sectional surveys may not allow to establish causation.

- Due to data limitation, the DBM was examined only at the population or national level.

underweight and 264 million women of reproductive age were affected by iron-amenable anaemia. ${ }^{2} 3$ These key indicators of DBM are also increasing globally, with the low-income and middle income countries (LMICs) being the most affected. ${ }^{4}$ For example, while globally, obesity has doubled in the last three decades, it has tripled in LMICs in just two decades. ${ }^{5}$ An analysis of survey data from 24 African countries spanning 25 years revealed that overweight and obesity among women are on the rise. ${ }^{6}$ Also, comparative analysis of data on women and men in the LMICs showed that DBM tends to disproportionately affect women than men. ${ }^{78}$ The vulnerability of women to DBM may be attributed to their high nutritional requirements for pregnancy and lactation and also because of gender inequalities in poverty. ${ }^{8}$ Further evidence suggests that if micronutrient deficiencies are taken into account, Africa is in fact experiencing a triple burden of malnutrition. ${ }^{23}$ It has been estimated that almost $50 \%$ of pregnant women in Africa suffer from anaemia, which increases the risk of death for themselves as well as their unborn babies. ${ }^{2}$ 
Furthermore, the contribution of DBM to the burden of disease has been documented. The available evidence suggests that underweight and obesity are among the top 10 leading risk factors for the global burden of disease. ${ }^{9}{ }^{10}$ Furthermore, more recent WHO data have identified underweight among the top four risks factors for the burden of disease in the world, as measured in disability-adjusted life years (DALYs) - contributing up to $6 \%$ of global DALYs. ${ }^{10}$ The relationship between maternal and child weight and the consequences on disease incidence later in life have also been documented. For example, being overweight as a mother is associated with overweight and obesity in their offspring. ${ }^{211}$ Rapid weight gain early in life may predispose to long-term excessive weight or obesity. And as the evidence suggests, obesity is an important underlying cause of many non-communicable diseases (NCDs), including hypertension, diabetes, cancer, stroke and ischaemic heart disease. ${ }^{35} 11$ These diseases are responsible for most of the deaths worldwide, with LMICs disproportionately bearing the brunt, where $80 \%$ of the NCD deaths occur. ${ }^{2-4}$ Experts warned that unless countries in Africa start enacting measures to tackle the DBM affecting the continent, the road towards universal healthcare (UHC) will be marred with obstacles as will the aspiration to achieve health and well-being for all by $2030 .^{12}$

It is important to underscore that DBM can exist at the individual, household and population levels. ${ }^{2}$ For instance, at the individual level, obesity can occur with deficiency of one or various vitamins and minerals, or overweight in an adult who was stunted during childhood. At the household level, a mother may be overweight or anaemic and a child or grandparent is underweight. DBM at the population level occurs when there is a prevalence of both undernutrition and overnutrition in the same community, nation or region. ${ }^{2}$ Since it will be difficult to determine individual and within households DBM using these data, our definition of DBM is at population or country level, whereby underweight and overweight/ obesity co-exist in the same country. Undoubtedly, the DBM offers an important opportunity for use of multidimensional approaches in tackling malnutrition in all its forms. Addressing the DBM will be key to achieving the Sustainable Development Goals (in particular Goal 2 and Target 3.4) and the Commitments of the Rome Declaration on Nutrition, within the UN Decade of Action on Nutrition. ${ }^{1}$ However, as a starting point, countries need to understand the key correlates of DBM. The present paper attempts to elucidate these correlates.

The factors influencing DBM are complex, ranging from biological to environmental factors. ${ }^{2}$ Some of these factors may include poor water and sanitation systems, weak public health systems thereby thwarting efforts to reduce undernutrition. ${ }^{2}$ Also, increasing urbanisation and changing dietary patterns and sedentary lifestyles, income level, older age, household wealth, higher education, place of residence among others have been identified as key contributing factors to the DBM epidemic. ${ }^{13-16}$
For example, Kamal and colleagues observed in their study that household wealth index and place of residence are key predictors of the DBM among women in Bangladesh. ${ }^{17}$ Women from the poorest wealth quintile were more likely to suffer from DBM relative to those from the richest wealth quintile. Besides, marital status, age at first childbirth, parity, household size and food security were also found to play a critical role in the DBM epidemic. ${ }^{141718}$ The above-referenced studies used data from a single country, masking differences and commonalities of the effects of the correlates on DBM across countries. Suffice to add that Neupane and colleagues ${ }^{19}$ attempted to investigate the problem of DBM using data sets from 32 sub-Saharan African (SSA) countries. This study, however, fell short of addressing DBM as it focused only on overweight and obesity. Second, the referenced study used only three variables (wealth quintile, place of residence and education) to predict overweight and obesity. The present study filled these gaps by simultaneously analysing underweight, overweight and obesity, using a comprehensive list of predictor variables, to provide a robust picture of the correlates of DBM in SSA.

Given the anticipated long-term effects of DBM, the factors that are associated with being underweight, overweight or obese should be considered while formulating effective interventions to address DBM among women. ${ }^{15} 16$ This stresses the need for prevention strategies targeted at addressing all forms of malnutrition. The present study is well positioned to provide evidence on the key correlates of DBM in SSA, which is currently lacking in the region. Understanding the role of these risk factors is key to developing clear and effective strategies for improving public health in SSA. The overarching aim of our study is to examine the correlates of DBM among women in five SSA countries.

\section{METHODOLOGY}

\section{Sources of data and sampling procedure}

Design and data sources

The study used the recent Demographic and Health Surveys (DHS) ${ }^{20}$ data from Ghana, ${ }^{21}$ Kenya (2014), Nigeria (2013), Mozambique (2011) and Democratic Republic of Congo (DRC) (2013-2014). The selection of these five countries was informed by our previous analysis. ${ }^{22}$ The DHS data are nationally representative, repeated cross-sectional household surveys collected primarily in LMICs approximately every 5 years, using standardised questionnaires to enable cross-country comparisons. ${ }^{23}{ }^{24}$ The design of the DHS surveys is identical across all participating countries, making possible the comparisons between and across countries. The DHS utilises a two-stage sample design. ${ }^{2125-28}$ The first stage involves the selection of sample points or clusters from an updated master sampling frame constructed from National Population and Housing Census of the respective countries. The clusters are selected using systematic sampling with probability proportional to size. 
Table 1 Characteristics of the BMI samples

\begin{tabular}{|c|c|c|c|c|c|}
\hline & DRC & Ghana & Kenya & Mozambique & Nigeria \\
\hline Variables & Mean/\% & Mean/\% & Mean/\% & Mean/\% & Mean/\% \\
\hline \multicolumn{6}{|l|}{ BMI } \\
\hline BMI <18.50 (underweight) & 12.70 & 5.30 & 11.80 & 5.70 & 8.70 \\
\hline BMI=25-29.99 (overweight) & 11.50 & 23.40 & 18.90 & 13.70 & 18.30 \\
\hline
\end{tabular}

BMI, body mass index; DRC, Democratic Republic of Congo.

Household listing is then conducted in all the selected clusters to provide a sampling frame for the second stage selection of households. The second stage of selection involves the systematic sampling of the households listed in each cluster and households to be included in the survey are randomly selected from the list. The rationale for the second stage selection is to ensure adequate numbers of completed individual interviews to provide estimates for key indicators with an acceptable precision. All men and women aged 15-59 and 15-49, respectively, in the selected households (men in half of the households) were eligible to participate in the surveys if they were either usual residents of the household or visitors present in the household on the night before the survey. We limited our analyses to women aged 15-49 years in all countries and who have complete anthropometry data. The samples for the respective countries are as follows: DRC (9506), Ghana (3012), Kenya (9993), Mozambique (11017) and Nigeria (31 170).

\section{ETHICS STATEMENT}

The DHS obtained ethical clearance from Government recognised Ethical Review Committees/Institutional Review Boards of the respective countries as well as the Institutional Review Board of ICF International, USA, before the surveys were conducted. Written informed consent was obtained from the women before participation. The authors of this paper sought and obtained permission from the DHS programme for the use of the data. The data were completely anonymised and therefore the authors did not seek further ethical clearance before their use.

\section{PATIENT AND PUBLIC INVOLVEMENT STATEMENT}

We used completely anonymised secondary data for the analysis. Therefore, no patients or public involvement can be reported.

\section{Outcome and predictor variables}

Outcome variables

The outcome variable of interest was women body mass index (BMI) derived from results of height and weight measurements. The height and weight were measured objectively by trained field technicians using standard techniques. ${ }^{24}$ Weight measurements were taken using electronic Seca scales with a digital screen, while height measurements were taken using a stadiometer produced by Shorr Productions. BMI, also referred to as Quetelet's Index, ${ }^{29}$ was derived by dividing weight in $\mathrm{kg}$ by the squared height in metres. Based on the BMI $\left(\mathrm{kg} / \mathrm{m}^{2}\right)$ estimates, and according to WHO guidelines ${ }^{30}$ the participants were classified as underweight (BMI $<18.50 \mathrm{~kg} / \mathrm{m}^{2}$ ), normal weight $\left(18.50-24.99 \mathrm{~kg} / \mathrm{m}^{2}\right)$, overweight $\left(25.0-29.9 \mathrm{~kg} / \mathrm{m}^{2}\right)$ and obese $\left(\geq 30.0 \mathrm{~kg} / \mathrm{m}^{2}\right)$. The normal weight $(18.50-$ $24.99 \mathrm{~kg} / \mathrm{m}^{2}$ ) was used as reference category in the analysis.

\section{Predictor variables}

The predictor variables of interest used in the analysis included, women's age, education, employment status, breastfeeding status, parity, place of residence, marital status, women decision making autonomy (decision on large household purchases and decision on health), household size, frequency of watching TV and household wealth index. These potential correlates were identified based on literature search and further subjected to bivariate analysis to establish their relationship with the DBM indicators. All statistically significant variables were included in the multivariable analysis.

\section{Analytical strategy}

We utilised multinomial logistic regression (MLR) in the analysis. MLR approach was contemplated to be suitable as the outcome measure is polychotomous by nature. Further, the MLR was considered attractive analytical technique because it does not assume normality, linearity, or homoscedasticity. ${ }^{31}$ In MLR, we observe vectors $Y=\left(y_{1}, y_{2}, \ldots, y_{k+1}\right)^{T} ; y_{i}=0$ for all $i$, and one $j$ with $y_{j}=1$ and corresponding probability $p_{j}$, implying

$$
\mathrm{EY}=\mathrm{p}, \operatorname{Cov} \mathrm{Y}=\Lambda_{p}=\left(\begin{array}{ccc}
p_{1} & \cdots & 0 \\
\vdots & \cdots & \vdots \\
0 & \cdots & p_{k+1}
\end{array}\right)
$$

The multinomial logistic regression is given by 
Table 2 Characteristics of the samples, categorical and continuous variables

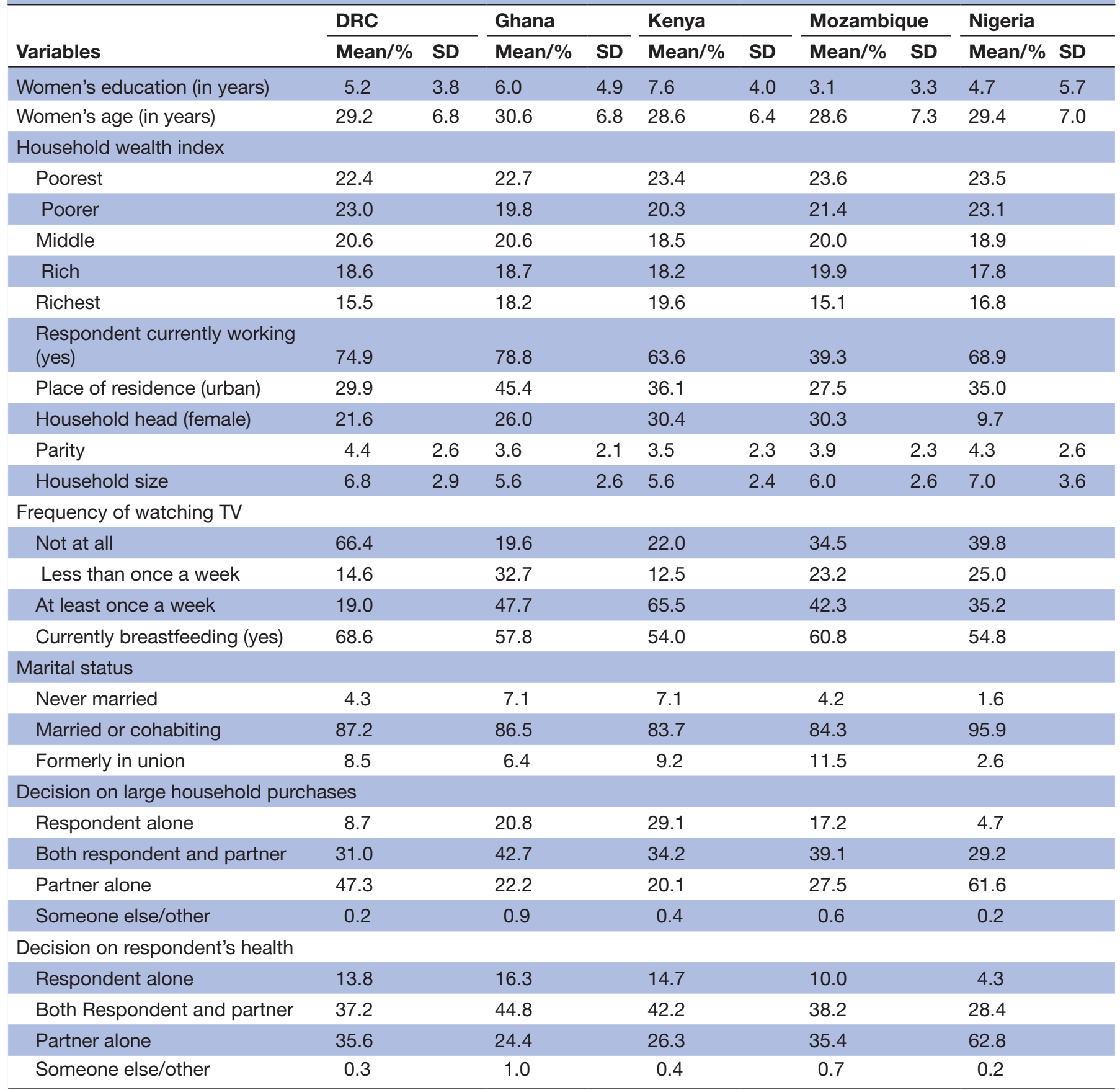

DRC, Democratic Republic of Congo.

$$
\begin{array}{r}
p_{i}=\frac{\exp \left(\pi^{(i)^{T}} x\right)}{1+\sum_{j=1}^{k} \exp \left(\pi^{(i)^{T}} x\right)} \text { for } \mathrm{i}=1, \ldots, \mathrm{k}(2) \\
p_{k+1}=\frac{1}{1+\sum_{j=1}^{k} \exp \left(\pi^{(i)^{T}} x\right)}
\end{array}
$$

where $x=\left(x_{1}, x_{2}, \ldots, x_{m}\right)^{T}$ is the vector of covariates, and $\Pi^{(\mathrm{i})}$ is the parameter vector corresponding to the i-th response category. In Equation (3), the parameters are set to zero and allows computing the probability for the base category in the MLR.

Because of the normalisation condition,

$$
\sum_{j=1}^{k} P\left(y^{(j)}=1 \mid x, \pi\right)=1
$$

the weight vector of one of the classes need not to be estimated without loss of generality, in this case the $(\mathrm{j}+1)$-th category. To perform maximum likelihood (ML), 
one simply maximises the log-likelihood function using Equation (5),

$$
\log \prod_{j=1}^{k+1} p_{j}^{y_{j}}=\sum_{j=1}^{k} y_{j} \pi^{(i)^{T}} x-\log \left[1+\sum_{j=1}^{k} \exp \left(\pi^{(i)^{T}} x\right)\right]
$$

The MLR model was constructed to investigate the net effects of the correlates on underweight, overweight and obesity. Using a BMI category of $18.5-24.99 \mathrm{~kg} /$ $\mathrm{m}^{2}$ (normal weight) as the reference, a set of logistic regressions for underweight, overweight and obese categories was estimated in which, each of the categories was contrasted with the reference category. All covariates were simultaneously entered into the model. Results were presented in the form of coefficients with significance levels and $95 \% \mathrm{CI}$.

\section{RESULTS}

\section{Descriptive}

The tables 1 and 2 present the characteristics of the samples. The results in table 1 show that among the

Table 3 Multivariable analysis of the association between sociodemographic correlates and malnutrition, DRC

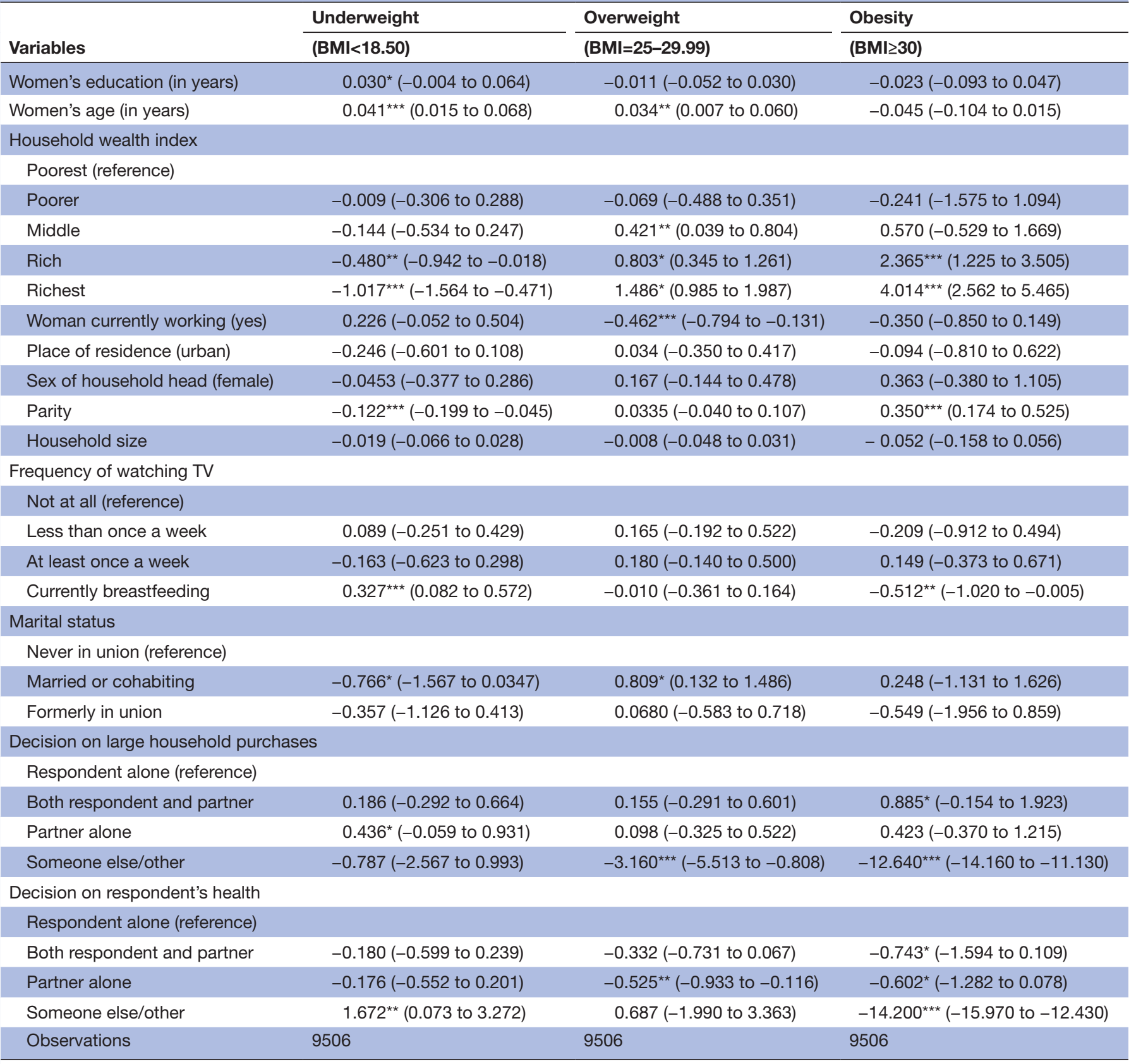

$\mathrm{Cl}$ in parentheses.

${ }^{*} \mathrm{P}<0.1 ;{ }^{* *} \mathrm{P}<0.05 ;{ }^{* * *} \mathrm{P}<0.01$

$\mathrm{BMI}$, body mass index; DRC, Democratic Republic of Congo. 
Table 4 Multivariable analysis of the association between sociodemographic correlates and malnutrition, Ghana

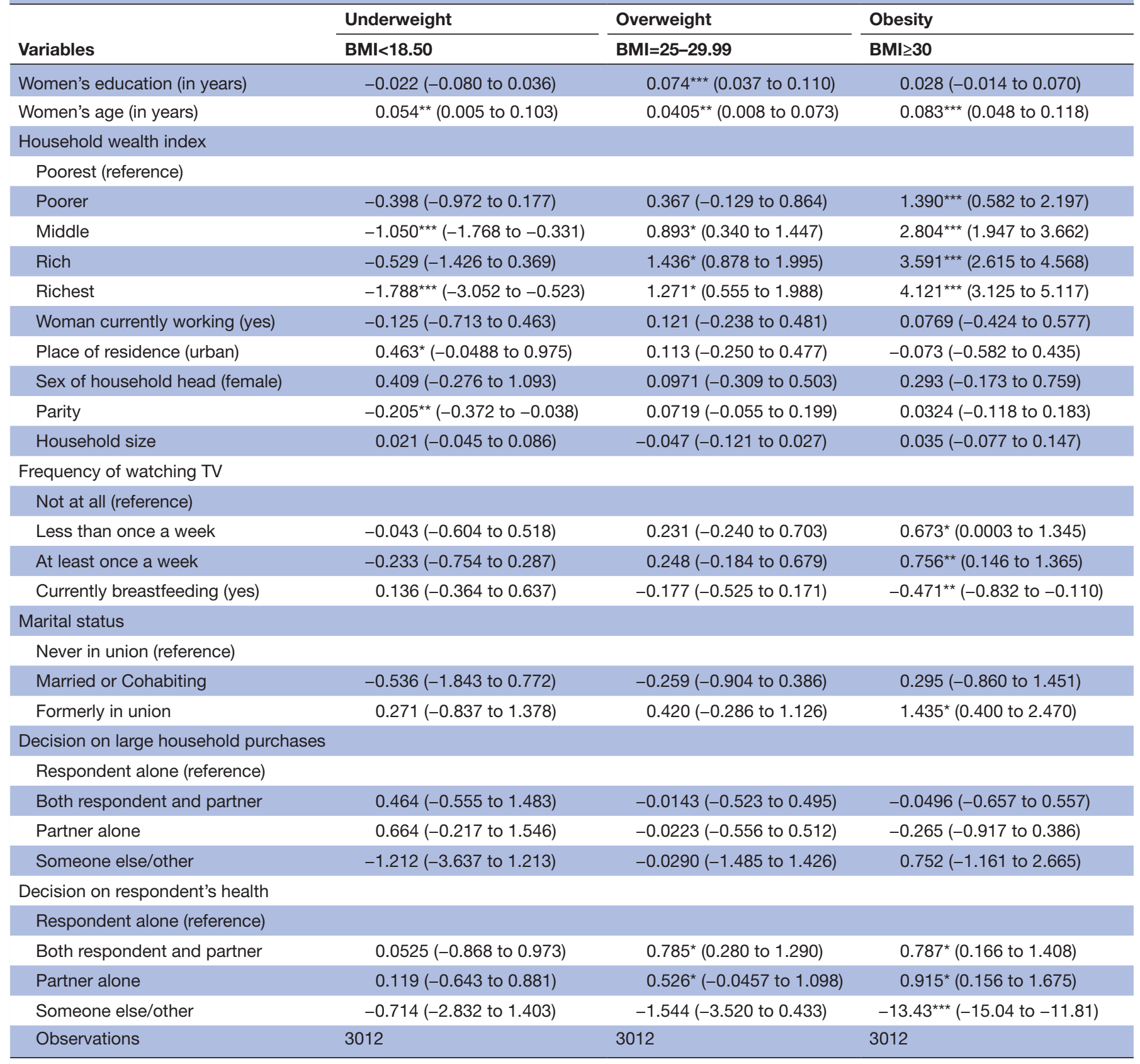

$\mathrm{Cl}$ in parentheses.

${ }^{*} \mathrm{P}<0.1 ;{ }^{* \star} \mathrm{P}<0.05 ;{ }^{* \star *} \mathrm{P}<0.01$.

$\mathrm{BMI}$, body mass index.

five countries, Mozambique had the highest number of normal weight women $(78 \%)$ followed by DRC $(74 \%)$, with Ghana having the lowest (59\%). Kenya (12\%) and DRC $(13 \%)$ had the highest prevalence of underweight women, while Ghana had the highest number of overweight $(23 \%)$ and obese $(12 \%)$ women. In all the countries analysed, the prevalence of overweight and obesity had overtaken underweight. In table 2, women in Kenya had more years of education, while Mozambique had women with the least years of education. The age of study participants was similar across all the five countries and ranged from 28 years in Mozambique and Kenya to 30 years in Ghana. Further, among all the countries, Ghana had the highest number of women who were working (79\%), while Mozambique had the lowest (39\%).

\section{Multivariable}

The tables 3-7 present the MLR results of the correlates of DBM among women in DRC, Ghana, Kenya, Mozambique and Nigeria. The results showed a significant positive relationship between women's years' of education and overweight in Ghana, both overweight and obesity in Mozambique and 
Table 5 Multivariable analysis of the association between sociodemographic correlates and malnutrition, Kenya

\begin{tabular}{|c|c|c|c|}
\hline & Underweight & Overweight & Obesity \\
\hline Variables & $(B M I<18.50)$ & (BMI=25.290.99) & $(\mathrm{BMI} \geq 30)$ \\
\hline Women's education (in years) & $-0.113^{\star \star \star}(-0.148$ to -0.078$)$ & $0.013(-0.016$ to 0.042$)$ & $0.013(-0.030$ to 0.056$)$ \\
\hline \multicolumn{4}{|l|}{ Household wealth index } \\
\hline \multicolumn{4}{|l|}{ Poorest (reference) } \\
\hline Rich & $-0.940^{\star \star \star}(-1.376$ to -0.504$)$ & $0.927^{\star}(0.578$ to 1.276$)$ & $1.690^{* \star *}$ (1.164 to 2.216$)$ \\
\hline Richest & $-1.307^{\star \star \star}(-1.946$ to -0.668$)$ & $1.427^{\star \star \star}(1.042$ to 1.813$)$ & $2.616^{\star \star \star}$ (2.049 to 3.184$)$ \\
\hline Woman currently working (yes) & $-0.357^{\star \star \star}(-0.590$ to -0.123$)$ & $0.0162(-0.221$ to 0.253$)$ & $0.210(-0.110$ to 0.529$)$ \\
\hline Place of residents (urban) & $0.0337(-0.272$ to 0.339$)$ & $0.107(-0.115$ to 0.330$)$ & $0.497^{\star \star \star}(0.177$ to 0.817$)$ \\
\hline \multicolumn{4}{|l|}{ Frequency of watching TV } \\
\hline \multicolumn{4}{|l|}{ Not at all } \\
\hline Less than once a week & $-0.539^{\star \star \star}(-0.905$ to -0.174$)$ & $0.076(-0.295$ to 0.447$)$ & $-0.131(-0.700$ to 0.439$)$ \\
\hline At least once a week & $-0.066(-0.355$ to 0.223$)$ & $0.043(-0.194$ to 0.281$)$ & $0.035(-0.357$ to 0.426$)$ \\
\hline Currently breastfeeding (yes) & $0.102(-0.112$ to 0.316$)$ & $-0.156^{\star}(-0.338$ to 0.026$)$ & $-0.204(-0.510$ to 0.102$)$ \\
\hline \multicolumn{4}{|l|}{ Marital status } \\
\hline \multicolumn{4}{|l|}{ Never in union (reference) } \\
\hline Married or cohabiting & $0.299(-0.197$ to 0.794$)$ & $0.870^{*}(0.422$ to 1.317$)$ & $0.898^{*}(0.212$ to 1.584$)$ \\
\hline Formerly in union & $0.209(-0.339$ to 0.756$)$ & $0.488^{\star \star}(0.047$ to 0.929$)$ & $0.312(-0.392$ to 1.017$)$ \\
\hline \multicolumn{4}{|l|}{ Respondent alone (reference) } \\
\hline Both respondent and partner & $-0.0559(-0.427$ to 0.315$)$ & $0.0704(-0.194$ to 0.335$)$ & $-0.131(-0.524$ to 0.262$)$ \\
\hline Partner alone & $-0.220(-0.601$ to 0.161$)$ & $-0.016(-0.301$ to 0.268$)$ & $-0.183(-0.633$ to 0.266$)$ \\
\hline Someone else/other & $-2.446^{\star \star \star}(-4.226$ to -0.666$)$ & $0.092(-2.677$ to 2.862$)$ & $-12.920^{\star \star \star}(-14.610$ to -11.230$)$ \\
\hline Observations & 9993 & 9993 & 9993 \\
\hline
\end{tabular}

$\mathrm{Cl}$ in parentheses.

${ }^{*} \mathrm{P}<0.1 ;{ }^{* \star} \mathrm{P}<0.05 ;{ }^{* \star *} \mathrm{P}<0.01$.

$\mathrm{BMI}$, body mass index.

Nigeria. Thus, compared with normal weight women, an additional year of education was associated with a higher likelihood of overweight and obesity in Ghana, Mozambique and Nigeria. Conversely, number of years of education was associated negatively with underweight in Kenya and Nigeria relative to normal weight. Also, older age was significantly and positively associated with underweight, overweight and obesity compared with normal weight women in all countries included in the analysis. An exception could be made of Nigeria where older age was inversely related to underweight. The results in relation to household wealth index were mixed. While generally, significant positive associations were observed between wealth index (middle, richer and richest quintiles) and overweight and obesity in all the five countries, inverse relationship was observed for underweight. Compared with normal weight women, higher maternal parity was inversely related to underweight in Ghana and Mozambique, and both underweight and overweight in Kenya. In DRC, maternal parity was inversely related to underweight and positively related to obesity. Breastfeeding was associated with less likelihood of underweight among women in DRC and Nigeria, obesity in DRC and Ghana, overweight in Kenya 
Table 6 Multivariable analysis of the association between sociodemographic correlates and malnutrition, Mozambique

\begin{tabular}{|c|c|c|c|}
\hline & Underweight & Overweight & Obesity \\
\hline Variables & $(B M I<18.50)$ & (BMI=25-29.99) & $(\mathrm{BMI} \geq 30)$ \\
\hline Women' education (yes) & $0.011(-0.041$ to 0.063$)$ & $0.044^{\star \star \star}(0.0127$ to 0.076$)$ & $0.098^{\star \star \star}(0.041$ to 0.156$)$ \\
\hline \multicolumn{4}{|l|}{ Household wealth index } \\
\hline \multicolumn{4}{|l|}{ Poorest (reference) } \\
\hline Rich & $-0.618^{\star \star \star}(-1.081$ to -0.154$)$ & $1.235^{\star}(0.818$ to 1.652$)$ & $2.905^{\star \star \star}(1.576$ to 4.234$)$ \\
\hline Richest & $-0.800^{\star \star \star}(-1.408$ to -0.192$)$ & $1.977^{\star \star \star}(1.517$ to 2.437$)$ & $4.832^{\star \star \star}(3.496$ to 6.168$)$ \\
\hline Woman currently working (yes) & $0.195(-0.087$ to 0.477$)$ & $-0.0795(-0.271$ to 0.112$)$ & $0.014(-0.371$ to 0.400$)$ \\
\hline Place of residence (urban) & $0.0766(-0.306$ to 0.459$)$ & $-0.0722(-0.350$ to 0.205$)$ & $-0.0180(-0.504$ to 0.468$)$ \\
\hline \multicolumn{4}{|l|}{ Frequency of watching TV } \\
\hline \multicolumn{4}{|l|}{ Not at all (reference) } \\
\hline Less than once a week & $-0.0113(-0.328$ to 0.306$)$ & $0.157(-0.091$ to 0.404$)$ & $0.630^{\star \star \star}(0.214$ to 1.047$)$ \\
\hline At least once a week & $-0.214(-0.518$ to 0.0895$)$ & $-0.0124(-0.213-0.188)$ & $0.044(-0.329$ to 0.418$)$ \\
\hline Currently breastfeeding & $0.215(-0.049$ to 0.478$)$ & $-0.298^{\star \star \star}(-0.493$ to -0.102$)$ & $-0.516^{\star \star}(-0.938$ to -0.0944$)$ \\
\hline \multicolumn{4}{|l|}{ Marital status } \\
\hline \multicolumn{4}{|l|}{ Never in union (reference) } \\
\hline Married or cohabiting & $0.253(-0.419$ to 0.925$)$ & $0.196(-0.223$ to 0.615$)$ & $0.708^{*}(-0.0469$ to 1.462$)$ \\
\hline Formerly in union & $0.351(-0.288$ to 0.989$)$ & $-0.029(-0.462$ to 0.404$)$ & $0.773^{\star *}(0.0197$ to 1.527$)$ \\
\hline \multicolumn{4}{|l|}{ Respondent alone (reference) } \\
\hline \multicolumn{4}{|l|}{ Respondent alone (reference) } \\
\hline Both respondent and partner & $-0.184(-0.633$ to 0.265$)$ & $-0.134(-0.425$ to 0.158$)$ & $-0.143(-0.777$ to 0.491$)$ \\
\hline Partner alone & $-0.317(-0.786$ to 0.151$)$ & $-0.148(-0.440$ to 0.144$)$ & $0.227(-0.360$ to 0.814$)$ \\
\hline Someone else/other & $-0.480(-1.477$ to 0.516$)$ & $-0.646(-1.649$ to 0.357$)$ & $-1.232(-3.319$ to 0.855$)$ \\
\hline Observations & 11017 & 11017 & 11017 \\
\hline
\end{tabular}

$\mathrm{Cl}$ in parentheses.

${ }^{*} \mathrm{P}<0.1 ;{ }^{* \star} \mathrm{P}<0.05 ;{ }^{* \star *} \mathrm{P}<0.01$.

$\mathrm{BMI}$, body mass index.

and overweight and obesity in Mozambique and Nigeria relative to normal weight women.

The figures 1 and 2 are pictorial presentations of the probability of women falling into underweight, overweight and obese categories if there were changes in their age and years of education.

\section{DISCUSSION}

This study investigated the correlates of DBM among women in five SSA countries. The key indicators of DBM used in the analysis were underweight, overweight and obesity. The results showed expectedly that there are some variations across countries on how the correlates included in this study are associated with DBM. Our analysis reveals that in Ghana, Mozambique and Nigeria, a higher number of years of formal education is associated with the likelihood of overweight and obesity relative to normal weight women. Thus, a higher number of years of education is a risk factor for women with unhealthy weight. This could be due to lifestyles changes as one achieve more years of education, which may include sedentary lifestyles and poor dietary patterns. ${ }^{32}$ Further, 
Table 7 Multivariable analysis of the association between sociodemographic correlates and malnutrition, Nigeria

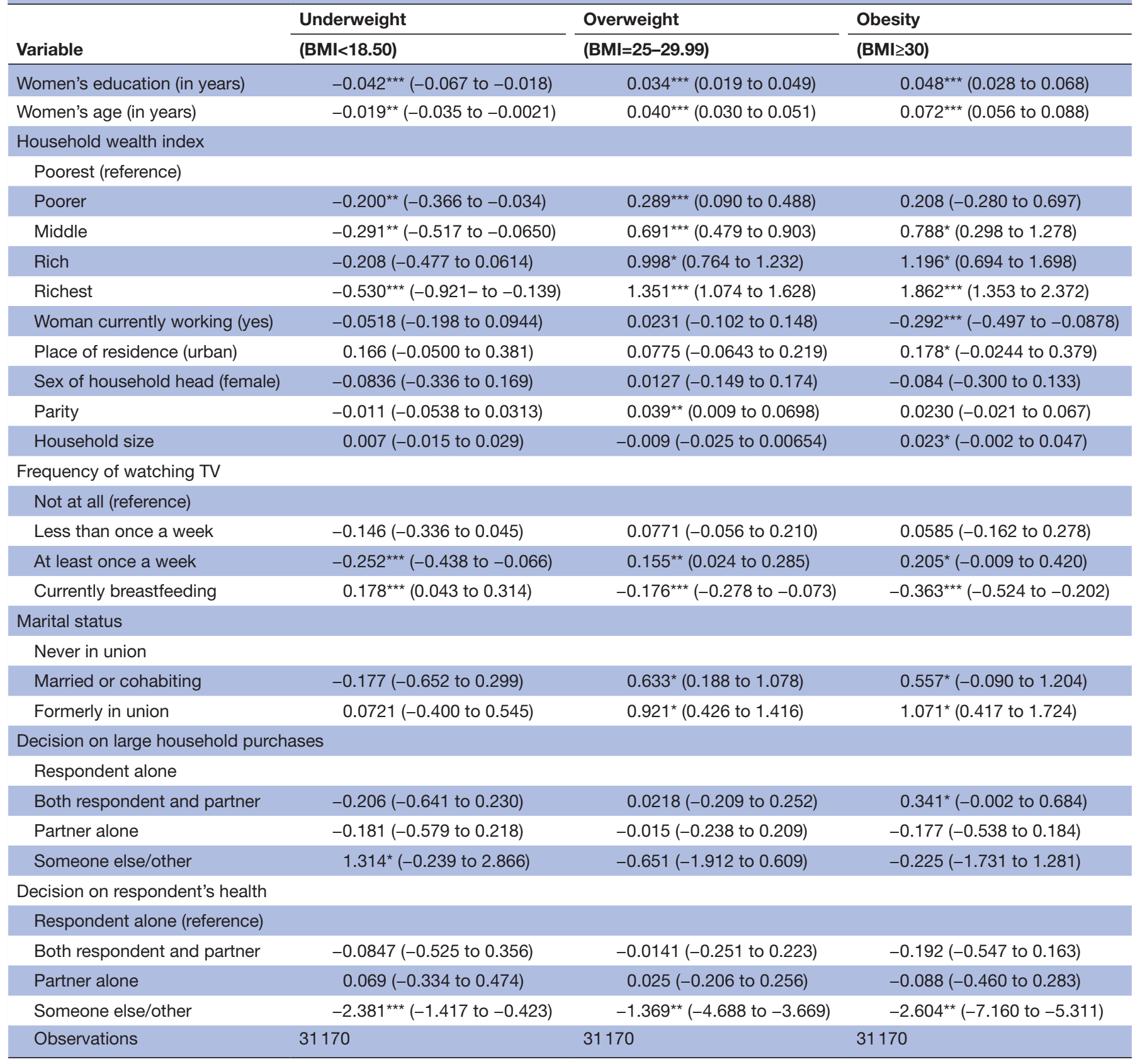

$\mathrm{Cl}$ in parentheses.

${ }^{*} \mathrm{P}<0.1 ;{ }^{* \star} \mathrm{P}<0.05 ;{ }^{* \star *} \mathrm{P}<0.01$.

$\mathrm{BMI}$, body mass index.

it could be that people who are already overweight or obese have higher propensity of adding more weight relative to those who have normal weight. In contrast, there was an inverse relationship between the number of years of formal education and underweight in Kenya and Nigeria. These findings are in line with previous studies. In Ghana, higher education was associated with overweight and obesity among women. ${ }^{33}$ Additionally, high education was associated positively with overweight among women in Indonesia. ${ }^{34}$ Nevertheless, in the same study, high education was associated with reduced risk of being underweight by $10 \%-30 \% \cdot{ }^{34}$ This is contrary to our findings in Kenya and Nigeria.

Furthermore, age was associated positively with all the DBM indicators across the five countries. Thus, older women are more likely to be overweight and obese and less likely to be underweight. This suggests that older age is a protective factor for underweight, while a risk factor for overweight and obesity. This positive correlation between age, overweight and obesity may have a consequential effect on non-communicable diseases (NCDs) among older people, as an unhealthy weight is a major 


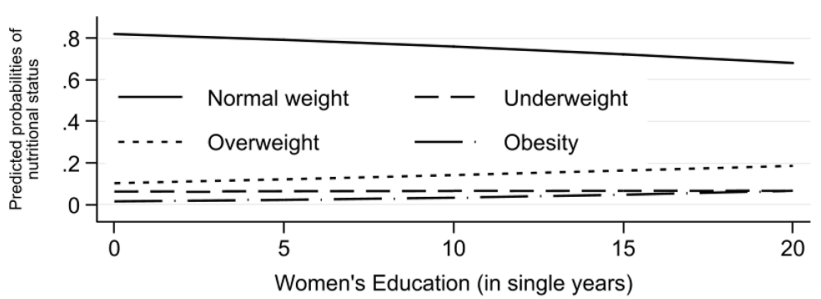

Source: 2013-2014 DHS D.R.Congo
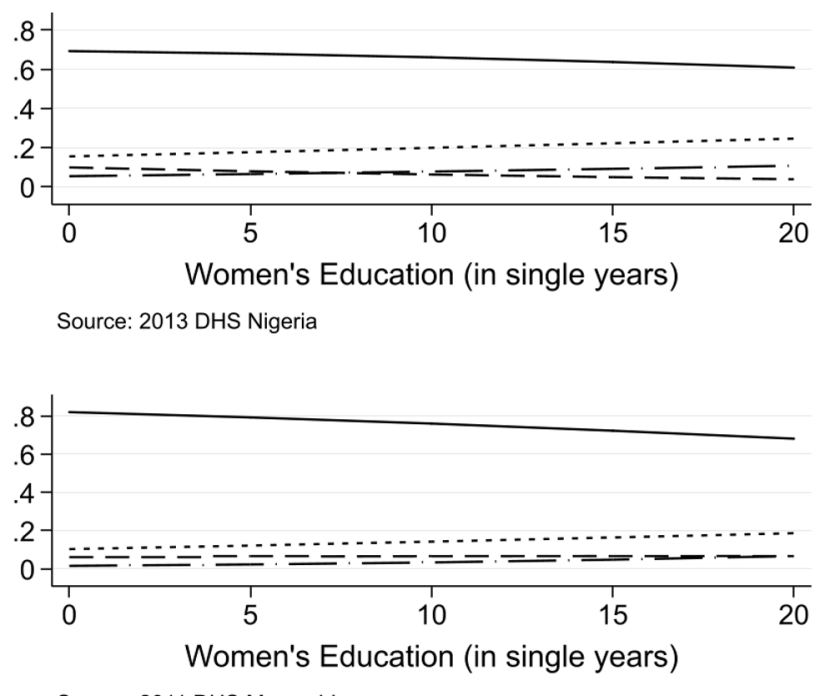

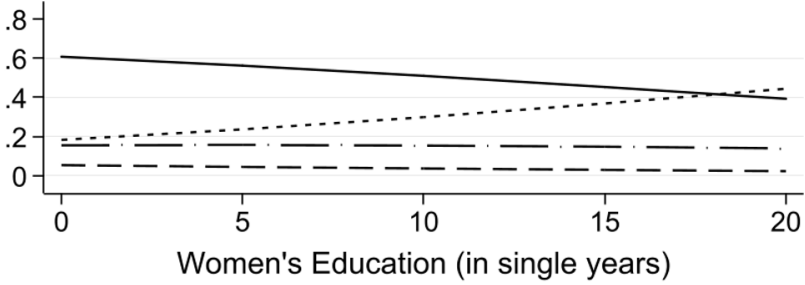

Source: 2014 DHS Ghana

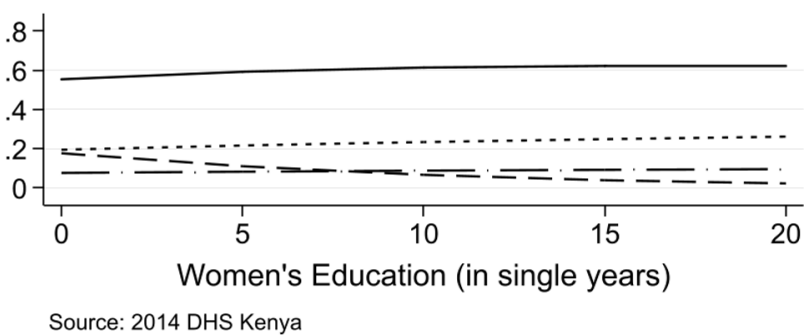

Source: 2014 DHS Kenya risk factor for NCDs. ${ }^{35-38}$ An exception to these findings could be made of Nigeria where older age was associated negatively with underweight women. This implies that in this setting, the older women become the more likelihood that they will suffer from underweight. The consequential effect of this may be poor health outcomes, as being underweight exposes women to higher risks of morbidity and mortality during pregnancy and child birth. ${ }^{39-41}$ The relationship between age and DBM has been documented in previous studies. For example, Doku and Neupane observed a significant positive association between age and the key indicators of DBM in Ghana. ${ }^{33}$ A study in Bangladesh observed a significant positive relationship between older age and DBM. ${ }^{42}$ These findings together with the findings from our study confirmed the contribution of age to the DBM epidemic.

Our analysis showed that household wealth index had mixed effects on DBM. In general, the three rich quintiles: middle, richer and richest were associated significantly and positively with overweight and obesity among women across all the countries included in the analysis. This may be due to obesogenic effects of increased household wealth as dietary pattern changes, ${ }^{43}$ and the fact that there is a documented positive correlation between household wealth and unhealthy body weight. ${ }^{44} 45$ In Bangladesh and Nepal, higher household wealth was associated with an increased likelihood of being overweight and obese. ${ }^{44}$ Also, being rich was associated with overweight and obesity among Ghanaian women. ${ }^{33}$ Interestingly, higher household wealth had an inverse effect on underweight. This inverse relationship may be due to the fact that most underweight women are likely to be in the poorer wealth quintiles ${ }^{46}$ and, therefore, may be unaffected by the higher household wealth quintiles. The inverse relationship has been observed previously. ${ }^{47}$ Relatedly, compared with the richest, women from the poorest households were significantly most likely to be underweight and least likely to be overweight over normal weight in Bangladesh. ${ }^{17}$ Suggesting that being in the poorest household is protective against overweight but not underweight. ${ }^{46}$

The health benefits of breastfeeding were illuminated in this study. Breastfeeding was found to associate with less likelihood of underweight, overweight and obesity in the five countries analysed. This suggests that mothers who have unhealthy weight should be encouraged to practice breastfeeding as the benefits are not only to their offspring but also for their own health and well-being. These findings confirm the widely recognised benefits of breastfeeding for improved health and developmental outcomes in mothers and their infants. ${ }^{4-51}$ The implication of this may be that interventions to promote breastfeeding may have positive impact on the DBM epidemic at the national level. The benefits of breastfeeding to women health have previously been documented. For example, breastfeeding has been suggested as an efficient means of 


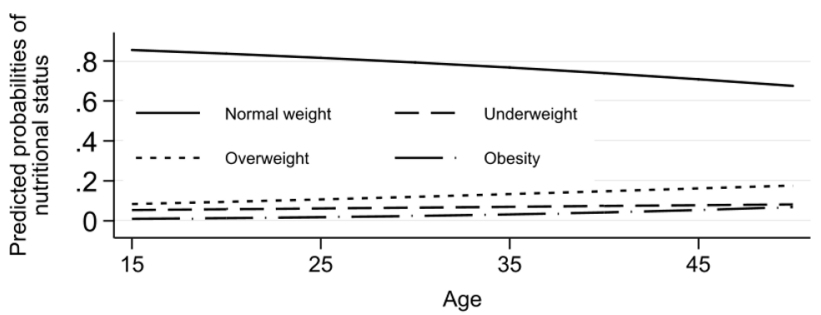

Source: 2013-2014 DHS D.R.Congo

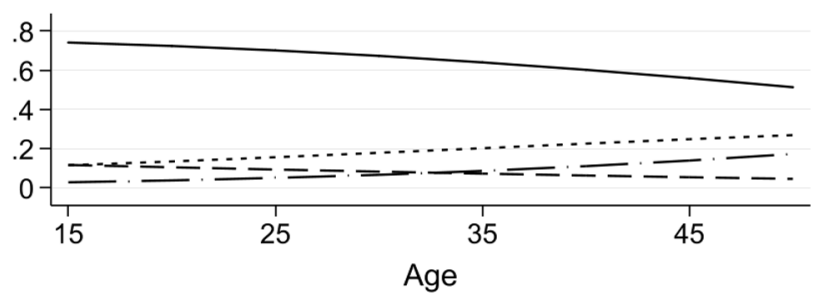

Source: 2013 DHS Nigeria

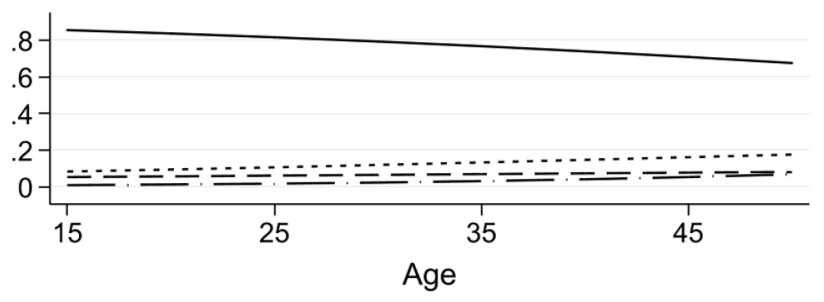

Source: 2011 DHS Mozambique

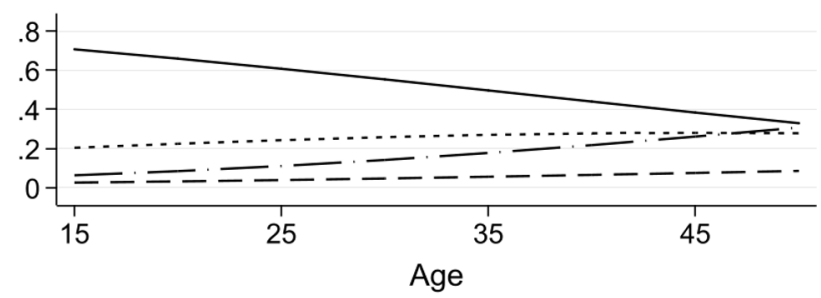

Source: 2014 DHS Ghana

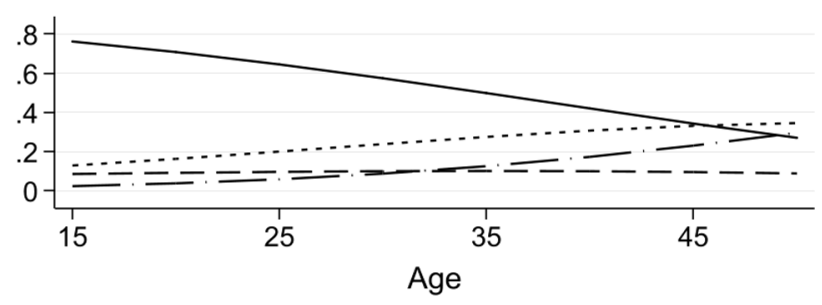

Source: 2014 DHS Kenya promoting postpartum weight loss due to its high energy cost. $^{52}$ Further evidence suggest that at 12 -weeks postpartum, exclusively breastfeeding (EBF) mothers had lost more total body weight than mixed feeding mothers. However, mixed feeding mothers lost slightly more per cent body fat than exclusively breastfeeding mothers. ${ }^{52}$ The authors concluded that EBF promotes greater weight loss than mixed feeding among mothers even in the early postpartum period. Several other studies have shown that EBF influences postpartum weight loss. ${ }^{51-54}$ The preceding discussion points to the need for health policymakers to design programmes to encourage mothers to breastfeed, especially, practice exclusive breastfeeding as a means of DBM prevention.

An important strength of our study is the use of large nationally representative samples, thereby providing more robust estimates of observed associations as well as enhancing the generalisability of the findings. The use of multicountry data help unmask differences and commonalities in the effects of the correlates on DBM across countries, which would not have been possible with single country data. Additionally, the height and weight data which were used to compute the BMI were objectively measured, reducing possible misclassification. A limitation worth mentioning is the cross-sectional nature of the data, which does not lends itself to the establishments of causal relationship between the predictor and outcome variables. The conclusions in the paper are therefore interpreted as mere associations between the predictor variables and the outcome variable. Another limitation is that due to data limitation, we were not able to examine DBM at the individual and within households. The analysis and interpretation in this paper are therefore limited to DBM at population or national level, whereby underweight, overweight and obesity coexist in the same country.

\section{CONCLUSIONS}

The study investigated the correlates of the DBM in five SSA countries. The analysis revealed that the effects of the correlates on DBM are largely similar across countries, except in few cases where there were disparities in the effects. The results indicate that higher number of years of education increases the likelihood of overweight and obesity among women in Ghana, Mozambique and Nigeria. Conversely, number of years of education is associated negatively with underweight in Kenya and Nigeria. Living in better-off households increases significantly the likelihood of overweight and obesity among women across all countries, while associated with the likelihood of underweight. Interventions to address DBM should take into account socioeconomic status. This may include providing special programmes for women who have unhealthy weight in wealthy households. A unit change in age is also associated significantly and positively with 
underweight, overweight and obesity in all the countries included in the analysis. Breastfeeding is associated with least likelihood of underweight, overweight and obesity in breastfeeding mothers. This implies that interventions to prevent DBM should incorporate breastfeeding to enhance their effectiveness.

Acknowledgements We wish to express our profound gratitude to The DHS Program, USA, for providing us access to the data. We also wish to acknowledge institutions of respective countries that played critical roles in the data collection process.

Contributors DAA conceived and designed the study. DAA and ZTD conducted the data analysis, interpreted the results and drafted the manuscript. CK contributed to study design, data analysis, interpretation and critical revision of the manuscript. All authors take responsibility of any issues that might arise from the publication of this manuscript.

Funding The authors have not declared a specific grant for this research from any funding agency in the public, commercial or not-for-profit sectors.

Competing interests None declared.

Patient consent for publication Not required.

Provenance and peer review Not commissioned; externally peer reviewed.

Data sharing statement This study was a re-analysis of existing data that are publicly available from The DHS Program at http://dhsprogram.com/publications/ publication-fr221-dhs-final-reports.cfm. Data are accessible free of charge upon a registration with the Demographic and Health Survey program (The DHS Program). The registration is done on the DHS website indicated above.

Open access This is an open access article distributed in accordance with the Creative Commons Attribution Non Commercial (CC BY-NC 4.0) license, which permits others to distribute, remix, adapt, build upon this work non-commercially, and license their derivative works on different terms, provided the original work is properly cited, appropriate credit is given, any changes made indicated, and the use is non-commercial. See: http://creativecommons.org/licenses/by-nc/4.0/.

\section{REFERENCES}

1. World Health Organization. Double burden of malnutrition. 2017 http://www.who.int/nutrition/double-burden-malnutrition/en/

2. Shrimpton R, Rokx C. The Double Burden of Malnutrition: A Review of Global Evidence. Health, Nutrition and Population Discussion Paper. World Bank, Washington, DC: World Bank, 2012. https:// openknowledge.worldbank.org/handle/10986/27417

3. NCD Risk Factor Collaboration (NCD-RisC). Trends in adult bodymass index in 200 countries from 1975 to 2014: a pooled analysis of 1698 population-based measurement studies with $19 \cdot 2$ million participants. Lancet 2016;387:1377-96.

4. Kolčić I. Double burden of malnutrition: A silent driver of double burden of disease in low- and middle-income countries. J Glob Health 2012;2:020303.

5. World Health Organization. Global Status Report on Noncommunicable diseases 2010. Geneva: WHO, 2011.

6. Amugsi DA, Dimbuene ZT, Mberu B, et al. Prevalence and time trends in overweight and obesity among urban women: an analysis of demographic and health surveys data from 24 African countries, 1991-2014. BMJ Open 2017;7:e017344.

7. Mendez MA, Monteiro CA, Popkin BM. Overweight exceeds underweight among women in most developing countries. Am J Clin Nutr 2005;81:714-21.

8. Delisle HF. Poverty: the double burden of malnutrition in mothers and the intergenerational impact. Ann N Y Acad Sci 2008;1136:172-84.

9. Guilbert JJ. The world health report 2002 - reducing risks, promoting healthy life. Educ Health 2003;16:230.

10. World Health Organization. Global health risks: mortality and burden of disease attributable to selected major risks. 2009 http://www.who. int/healthinfo/global_burden_disease/GlobalHealthRisks_report_full. pdf

11. Delisle H. Early nutritional influences on obesity, diabetes and cardiovascular disease risk. International Workshop, 6-9 June 2004, Montreal University, Quebec, Canada. Maternal and Child Nutrition 2005;1:128-9.

12. World Health Organization. Urgent action needed to tackle the double burden of malnutrition and to achieve Universal Health
Coverage and Sustainable Development Goals in Africa. 2018 https://www.afro.who.int/news/urgent-action-needed-tackledouble-burden-malnutrition-and-achieve-universal-healthcoverage

13. Kennedy G, Nantel G, Shetty P. Assessment of the double burden of malnutrition in six case study countries. http://www.fao.org/docrep/ 009/a0442e/a0442e03.htm\#TopOfPage

14. Hasan M, Sutradhar I, Shahabuddin A, et al. Double Burden of Malnutrition among Bangladeshi Women: A Literature Review. Muacevic A, Adler JR, eds. 9, 2017. Cureus.

15. Sarma H, Saquib N, Hasan MM, et al. Determinants of overweight or obesity among ever-married adult women in Bangladesh. BMC Obes 2016;3:13.

16. Zeba AN, Delisle HF, Renier G, et al. The double burden of malnutrition and cardiometabolic risk widens the gender and socioeconomic health gap: a study among adults in Burkina Faso (West Africa). Public Health Nutr 2012;15:2210-9.

17. Kamal SM, Hassan $\mathrm{CH}$, Alam GM. Dual burden of underweight and overweight among women in Bangladesh: patterns, prevalence, and sociodemographic correlates. J Health Popul Nutr 2015;33:92-105.

18. Kimani-Murage EW, Muthuri SK, Oti SO, et al. Evidence of a Double Burden of Malnutrition in Urban Poor Settings in Nairobi, Kenya. PLoS One 2015;10:e0129943.

19. Neupane S, Prakash KC, Doku DT. Overweight and obesity among women: analysis of demographic and health survey data from 32 Sub-Saharan African Countries. BMC Public Health 2016;16:30.

20. The DHS Program. Demographic and Health Surveys. http:// dhsprogram.com/data/available-datasets.cfm

21. Ghana Statistical Service (GSS), Ghana Health Service (GHS), ICF International. Ghana Demographic and Health Survey 2014. Rockville, Maryland, USA: GSS, GHS, and ICF International, 2015.

22. Amugsi DA, Dimbuene ZT, Kimani-Murage EW, et al. Differential effects of dietary diversity and maternal characteristics on linear growth of children aged 6-59 months in sub-Saharan Africa: a multicountry analysis. Public Health Nutr 2017;20:1029-45.

23. The DHS Program. Demographic and Health Surveys. https:// dhsprogram.com/data/dataset_admin/download-datasets.cfm (cited 9 Jun 2018).

24. The DHS Program. DHS Methodology. http://dhsprogram.com/WhatWe-Do/Survey-Types/DHS-Methodology.cfm

25. Ghana Statistical Service (GSS), Ghana Health Service (GHS), ICF Macro. GhanaDemographic and Health Survey 2008 Accra, Ghana: GSS, GHS, and ICF Macro, 2009.

26. Ministry of Health and Social Services (MoHSS), Macro International Inc. Namibia Demographic and Health Survey 2006-07 Windhoek, Namibia and Calverton. Maryland, USA: MoHSS and Macro International Inc, 2008.

27. National Population Commission (NPC) [Nigeria], ICF International. Nigeria Demographic and Health Survey. Abuja, Nigeria, and Rockville, Maryland, USA: NPC and ICF International, 2014.

28. National Bureau of Statistics-Kenya, ICF International. 2014 KDHS Key Findings. Rockville, Maryland, USA: KNBS and ICF International, 2015.

29. Eknoyan G. Adolphe Quetelet (1796-1874)--the average man and indices of obesity. Nephrol Dial Transplant 2008;23:47-51.

30. World Health Organization. BMI classification: WHO, 2006. Available from. http://apps.who.int/bmi/index.jsp?introPage=intro_3.html

31. Starkweather J, Moske KA. Multinomial Logistic Regression, 2011. Available from. https://it.unt.edu/sites/default/files/mlr_jds_aug2011. pdf

32. Kautzky-Willer A, Dorner T, Jensby A, et al. Women show a closer association between educational level and hypertension or diabetes mellitus than males: a secondary analysis from the Austrian HIS. BMC Public Health 2012;12:392.

33. Doku DT, Neupane S. Double burden of malnutrition: increasing overweight and obesity and stall underweight trends among Ghanaian women. BMC Public Health 2015;15:670.

34. Hanandita W, Tampubolon G. The double burden of malnutrition in Indonesia: Social determinants and geographical variations. SSM Popul Health 2015;1:16-25.

35. Kunutsor S, Powles J. Descriptive epidemiology of blood pressure in a rural adult population in Northern Ghana Rural Remote Health. 2009:9:1095.

36. Agyemang C. Rural and urban differences in blood pressure and hypertension in Ghana, West Africa. Public Health 2006;120:525-33.

37. Van Middendorp D, Asbroek A, Bio FY, et al. Rural and urban differences in blood pressure and pregnancy-induced hypertension among pregnant women in Ghana Globalization and Health. 2013;9:59.

38. Nichols SR, Hypertension EP. In: Murray CJL, Lopez AD, eds. Quantifying Global Health Risks: the Burden of Disease Attributable 
to Selected Risk Factors. Cambridge, Massachusetts: Harvard University Press, 1996.

39. Negoro $\mathrm{H}$, Sugino $\mathrm{Y}$, Nishizawa $\mathrm{K}$, et al. Underweight body mass index is a risk factor of mortality in outpatients with nocturia in Japan. BMC Res Notes 2015;8:490.

40. Park D, Lee JH, Han S. Underweight: another risk factor for cardiovascular disease?: A cross-sectional 2013 Behavioral Risk Factor Surveillance System (BRFSS) study of 491,773 individuals in the USA. Medicine 2017;96:e8769.

41. Victora CG, Adair L, Fall C, et al. Maternal and child undernutrition: consequences for adult health and human capital. Lancet 2008;371:340-57.

42. Oddo VM, Rah JH, Semba RD, et al. Predictors of maternal and child double burden of malnutrition in rural Indonesia and Bangladesh. Am J Clin Nutr 2012;95:951-8.

43. Aitsi-Selmi A, Bell R, Shipley MJ, et al. Education modifies the association of wealth with obesity in women in middle-income but not low-income countries: an interaction study using seven national datasets, 2005-2010. PLoS One 2014;9:e90403.

44. Bishwajit G. Household wealth status and overweight and obesity among adult women in Bangladesh and Nepal. Obes Sci Pract 2017;3:185-92.

45. Balarajan Y, Villamor E. Nationally representative surveys show recent increases in the prevalence of overweight and obesity among women of reproductive age in Bangladesh, Nepal, and India. J Nutr 2009;139:2139-44.
46. Tebekaw $\mathrm{Y}$, Teller $\mathrm{C}$, Colón-Ramos U. The burden of underweight and overweight among women in Addis Ababa, Ethiopia. BMC Public Health 2014;14:1126.

47. Selvamani $Y$, Singh P. Socioeconomic patterns of underweight and its association with self-rated health, cognition and quality of life among older adults in India. PLoS One 2018;13:e0193979.

48. Jonas W, Nissen E, Ransjö-Arvidson AB, et al. Short- and longterm decrease of blood pressure in women during breastfeeding Breastfeed Med. 2008;3:103-9.

49. Handlin L, Jonas W, Ransjö-Arvidson AB, et al. Influence of common birth interventions on maternal blood pressure patterns during breastfeeding 2 days after birth Breastfeed Med. 2012;7:93-9.

50. Stuebe AM, Schwarz EB, Grewen K, et al. Duration of lactation and incidence of maternal hypertension: a longitudinal cohort study. Am J Epidemiol 2011;174:1147-58.

51. Sámano R, Martínez-Rojano H, Godínez Martínez E, et al. Effects of breastfeeding on weight loss and recovery of pregestational weight in adolescent and adult mothers. Food Nutr Bull 2013;34:123-30.

52. Hatsu IE, McDougald DM, Anderson AK. Effect of infant feeding on maternal body composition. Int Breastfeed J 2008;3:18.

53. López-Olmedo N, Hernández-Cordero S, Neufeld LM, et al. The associations of maternal weight change with breastfeeding, diet and physical activity during the postpartum period. Matern Child Health $J$ 2016;20:270-80.

54. Schalla SC, Witcomb GL, Haycraft E. Body shape and weight loss as motivators for breastfeeding initiation and continuation. Int $J$ Environ Res Public Health 2017;14. 